\title{
$\bigwedge_{\text {GEOGRÁFICO }}$ ISSN: $1982-1956$ \\ http://www.revistas.ufg.br/index.php/atelie
}

\section{Geossímbolos, saberes e práticas da cultura da pesca vernacular na paisagem ribeirinha do Pitangui-Jotuva, região dos Campos Gerais Paranaense}

\author{
Geosymbols, knowledge, and practices of local fishing culture \\ in the Pitangui-Jotuva riverside landscape, region of Campos \\ Gerais, Paraná, Brazil
}

\section{Geosymbols, savoirs et practices de la pesch vernaculaire dans le paysage rivière du Pitangui-Jotuva, región des Campos Gerais, Paraná, Brésil}

\author{
Carlos Roberto Scheibel \\ Universidade Estadual de Ponta Grossa \\ schei@superig.com.br \\ Nicolas Floriani \\ Universidade Estadual de Ponta Grossa \\ florianico@gmail.com
}

\begin{abstract}
Resumo
Este trabalho apresenta um estudo de caso sobre a cultura da pesca de lazer no Rio Pitangui, praticada por habitantes da região rural dos Campos Gerais (PR) e sua relação simbólica e material com a paisagem ribeirinha. O estudo aponta para a particularidade histórico-geográfica dessa prática sociocultural tradicional, cuja reprodução depende exclusivamente do resgate da memória dos moradores que possuem um estreito vínculo de pertencimento com o território da pesca de lazer, sendo atualmente ameaçado com a implantação definitiva do Parque nacional dos Campos Gerais, bem como outros processos de ordem socioeconômica que atingem o meio rural. A abordagem cultural, alicerçada na etnografia e na interpretação das representações espaciais, possibilitou o entendimento da diversidade de práticas e dos saberes locais acerca da paisagem fluvial do Rio Pitangui. Os geossímbolos da pesca vernacular (artefatos, itinerários técnicos, arquitetura dos 'ranchos' e acampamentos de pesca, dos caminhos que unem os pontos de pesca entre si) ligam-se ao corpo de conhecimentos sobre os ambientes propícios à pesca e ao sistema de classificação da ictiofauna local, transmitido oralmente a um determinado grupo de habitantes que tem construído uma história de pertencimento com o lugar. Este sistema de saberes e
\end{abstract}


fazeres é cotidianamente ressignificado frente aos fenômenos de urbanização, adaptando-se e apropriando-se também às tecnologias modernas da pesca de lazer. $\mathrm{O}$ território da pesca vernacular é permeado por novas territorialidades associadas ao fluxo migratório de turistas provindo do centro urbano nos finais de semana.

Palavras-chaves: Geossímbolos; Práticas e saberes locais de pesca; Paisagem ribeirinha; Mundo rural.

\begin{abstract}
This paper presents a study about the knowledge and practices of local fishing culture in the Rio Pitangui landscape, a rural region of Campos Gerais, State of Paraná, Brazil. The study points to historical and geographical particularities of this traditional sociocultural practice, whose reproduction depends solely on the revival of reminiscences of residents who have a close bond of belonging to the territory, currently being threatened by the installation of a National Park, as well as other processes of socioeconomic order which affect rural areas. The cultural approach is done grounded on ethnography and spatial representations, enabled by the understanding of the diversity of practices and of local knowledge about the Rio Pitangui river landscape. The geosymbols of local fishing culture, for example, the artifacts, technical routes, the architecture of fishing stocks and camps, which become paths connecting the points of fishing areas are bonded by the environmental knowledge which includes a system of local icthyofauna classification transmitted orally to a certain group of people who has built a history of belonging to those sites. This system of knowledge and practice is routinely reframed in terms of meanings vis-à-vis the phenomena of urbanization, adapting to and appropriating itself from the modern fishery technologies. The territory of traditional fishing is permeated by new territoriality associated with the flux of tourists coming from the urban centers during the weekends.
\end{abstract}

Keywords: Local fishing culture; Geosymbols; Traditional ecological knowledge; Campos Gerais Region.

\title{
Resumé
}

Cet article présente une étude de cas sur la culture de la pêche récréative à Rio Pitangui pratiquée par les habitants de la région rurale de Campos Gerais (état du Paraná, Brésil) et sa relatión symbolique et matérielle portant sur le paysage de la rivière. L'étude met en evidence la particularité historique et géographique de cette pratique socioculturelle traditionnelle dont la reproduction dépend de la récupération de la mémoire des résidents qui ont un lien étroit d'appartenance au territoire de la pêche récréative, actuellement menacés pour la creatión du Parc National de Campos Gerais ainsi comme d'autres processus d'ordre socio-économique qui frappent la zone rurale. L'approche culturelle, fondée sur l'ethnographie et l'interprétation des représentations spatiales a permit la compréhension de la diversité des pratiques et des savoirs vernaculaires sur le paysage de la rivière de Rio Pitangui . Les geosymboles de la pêche locale (les artefacts, les itinéraires techniques, l'architecture de « ranchos » et des camps de pêche, les chemins reliant les points de pêche ou les 'ranchos') s'attachent à l'ensemble des connaissances sur les environnements pròpres à la pêche ainsi comme sur le niveau du système de classification de la faune locale, transmises oralement à un certain groupe de personnes qui a construit une histoire d'appartenance au paysage. Ce système des pratiques et savoirs locales est régulièrement mit en confrontation par rapport aux phénomènes d'urbanisation et de l'introductión des technologies de la pêche modérne. Le territoire de la pêche vernaculaire est également empreint d'une nouvelle territorialité associée à la migration des touristes qui vienent des centres urbains pendant le week-end.

Mots-clés: territoire de la pêche vernaculaire ; geosymboles; savoirs écologiques locaux; Région de Campos Gerais (Brésil). 


\section{Introdução}

No presente texto, trataremos de apresentar os resultados de um estudo um estudo de caso sobre as formas de reprodução da cultura da pesca ribeirinha de lazer no Rio Pitangui e represa dos Alagados, região rural dos Campos Gerais (estado do Paraná). O trabalho situa-se na discussão sobre as formas de entendimento dos fenômenos socioculculturais pelo viés da abordagem da nova geografia cultural que, de acordo com Correa e Rosendhal (2010), deve recolocar no centro dos estudos culturais a relação homem-natureza de maneira a incluir tanto a dimensão material da cultura como a não-material, tanto o presente como o passado, os aspectos concebidos como os vivenciados, objetivos como intersubjetivos.

Nesse sentido, o estudo da prática da pesca ribeirinha de lazer envolveu a compreensão das dimensões culturais (os fazeres e os saberes compartilhados e reproduzidos por determinado grupo) e também o entendimento dos processos de ordem natural que compõem a paisagem enquanto sistema socioecológico. Buscou-se abordar a pesca ribeirinha local enquanto um complexo fenômeno de dimensões sociais e naturais - ligadas ao modo de vida rural - que convergem para formas peculiares de apropriação social da natureza, condicionadas também pelos processos de ordem ecológica que limitam, ou possibilitam, o desenvolvimento das atividades humanas sobre o território.

A prática da pesca e as inquietações dos autores sobre "quem são" esses pescadores que frequentam o rio Pitangui e o Reservatório de Alagados, "quais são suas práticas" e "como esse grupo interage com a paisagem ribeirinha", "como a pesca possibilita identificar e manter coeso um grupo social" e "como alimenta e dá vida a um imaginário de vida rural para os usuários - incluindo moradores urbanos - da paisagem ribeirinha", são questões que guiaram o processo investigativo.

Para tanto, o estudo exigiu uma interação efetiva do investigador com universo pesquisado. A observação participante permitiu evidenciar as formas de relação dos usuários com a paisagem fluvial ${ }^{1}$, traduzir histórias de vida a partir da recomposição de memórias, elaborar um modelo do corpo de conhecimentos e práticas locais da pesca vernacular ribeirinha e as formas de socialização, gerar hipóteses sobre as formas de reprodução e adaptação dessa prática tradicional que ocorrem na própria barranca do rio.

Com base na problemática acima destacada, alguns objetivos foram elaborados convergindo para o entendimento das especificidades da prática

\footnotetext{
${ }^{1}$ De acordo com A paisagem fluvial pode ser compreendida como a área marginal ao rio e que é por ele influenciada. É um espaço carregado de história, cultura e simbolismo (Pinto, 2005).
} 
sociocultural da pesca ribeirinha vernacular do Rio Pitangui e Represa de Alagados: a identificação das marcas (geossímbolos) na paisagem fluvial, o entendimento dos condicionantes ecossistêmicos sobre as práticas da pesca, a interpretação dos sentidos (as matrizes) da paisagem fluvial edificantes de valores tradicionais e de reafirmação da identidade socioterritorial dos habitantes de uma região rural, e as formas de adaptação e reprodução desta prática socioterritorial frente aos processos de urbanização e territorialidade da pesca turística moderna.

\section{A percepção e representação da paisagem ribeirinha e as matrizes cognitivas da prática da pesca vernacular}

A paisagem ribeirinha, ou fluvial, pode ser compreendida em termos físico-naturais como a área marginal aos topos e encostas e marginal ao rio, sendo por ambos influenciada. A complexidade da paisagem fluvial envolve, contudo, a diversidade de processos de ordem natural e social, mais ou menos interdependentes.

Dentre os elementos geobiocenóticos constam as interconexões entre: vegetação ripária (contato entre floresta ombrófila mista aluvial e as formações estépicas), a geomorfologia fluvial (compreendendo a diversidade de formas como os diques aluviais, as planícies de inundação, os terraços aluvionares), os solos hidromórficos (gleissolos, neossolos quartzarênicos e flúvicos, organossolos, cambissolos gleicos), que garantem uma relativa estabilidade ao funcionamento e estrutura do sistema frente às perturbações (distúrbios) que podem ser de origem natural ou antrópica.

Em termos geoantropológicos, a perturbação implica a interação sociocultural de uma determinada etnia com o mundo natural. Com sua realidade sensorial e material os seres humanos, de acordo com Denis Consgrove (2010),

[...] experienciam e transformam o mundo natural em mundo humano; (...) essa apropriação simbólica e material do mundo produz estilos de vida (genres de vie) distintos e paisagens distintas, que são histórica e geograficamente específicas. (COSGROVE, 2010, p. 103).

A apropriação social da natureza, por sua vez, remete à construção da identidade coletiva com o lugar, construído a partir das relações socais estabelecidas entre os indivíduos e das experiências cotidianas e espaços vividos, sendo repletos de subjetividades expressas em códigos, rituais, símbolos. Configuram-se, assim os espaços identitários, os lugares do sagrado (natureza) e do profano (homem); espaços derivados das tensões e conflitos 
sociais, os não lugares, espaços do medo e violência e as representações coletivas destes.

A análise de como o ser se relaciona com o lugar habitado é descrita por Gaston Bachelard em sua obra 'Poética do Espaço', de 1957, na qual discute as repercussões simbólicas das imagens dos lugares no inconsciente; noção similar é utilizada também por Y-Fu Tuan (1980), quando utiliza o termo topofilia para designar "a atração que o ser humano sente por características do meio, no que esse autor denominou de topofilia, com o significado de 'espaço de nossa felicidade" (TUAN, 1980, p.107), expressando o que Eric Dardel (2011) chama de geograficidade, ou seja, a essência geográfica do ser-e-estar-no-mundo, enquanto base da existência e da experiência geográfica (fenomenológica) da paisagem e do lugar.

Os símbolos edificados na paisagem - os geossímbolos - evidenciam a topofilia e a geograficidade de habitantes da zona rural (agricultores em sua maioria) que constroem sua história de vida com o lugar. Na caracterização dos pontos de pesca, a paisagem fluvial vai sendo configurada através da criação e reorganização das práticas socioculturais no território rural, para além das práticas materiais (no caso, agrícola).

Os geossímbolos do território da pesca ribeirinha de lazer - que fazem parte da relação do grupo de agricultores com a barranca do rio - são códigos a serem decifrados pelo pesquisador, que busca nas marcas da paisagem, os lugares valorizados no passado e vivenciados no cotidiano. A percepção desses símbolos paisagísticos por parte do investigador é guiado e condicionado por um filtro cultural e, portanto, socialmente mediado por valores não somente científicos, mas tradicionais, estéticos, afetivos, religiosos.

Os geossímbolos são definidos por Jöel Bonnemaison (2002) como sendo “(...) um lugar, um itinerário, uma extensão que, por razões políticas, religiosas ou culturais, aos olhos de certas pessoas e grupos étnicos assume um dimensão simbólica que os fortalece em sua identidade." (BONNEMAISON, 2002, p.109).

A partir desse conceito pode-se inferir que as marcas e artefatos existentes em qualquer paisagem podem e devem ser consideradas como geossímbolos, e, de acordo com Bonnemaison (2002, p. 124), para quem o espaço de existência dos geossímbolos é "uma forma de linguagem, um instrumento de comunicação partilhado por todos e, em definitivo, o lugar onde se inscreve o conjunto da visão cultural". Dessa forma, as paisagens retêm a atenção de quem as observa, uma vez que ela se constitui no suporte das representações individuais e sociais dos indivíduos e grupos de indivíduos que criam/recriam os mesmos territórios que as compõem. 
A paisagem, por outro lado, pode ser compreendida como um texto escrito por múltiplos atores. Nesse sentido, Denis Cosgrove (2010) fala da produção simbólica como produção de linguagem, sustentada por códigos de comunicação que vão além do seu sentido formal da palavra escrita ou falada. Cabem na lista de produções simbólicas o gesto, o vestuário, a conduta pessoal e social, a pintura, o ritual, as construções "através das quais mantemos o nosso mundo vivido, porque toda atividade humana é ao mesmo tempo material e simbólica, produção e comunicação" (COSGROVE, 2010, p. 103).

Nesses termos, captar os diversos textos (e narrativas) acerca das realidades espaço-temporais que se cristalizam na paisagem ribeirinha, exige, portanto, o esforço de decodificar os símbolos e seus significados coletivamente compartilhados por dado grupo social.

Para Maciel (2002), a hermenêutica aparece como a interpretação de um trabalho discursivo de ordenamento da imagem de mundo, possibilitando por meio dela

[...] desvendar como o imaginário da natureza é decodificado em valores simbólicos economicamente materializados, pois as práticas espaciais da humanidade não podem ser vistas como meramente racionais. Penetrar nas representações é compreender o espaço tanto através dos processos visíveis, quanto por meio dos aspectos míticos dos lugares, e a paisagem pode ser fundamental nesta conexão obrigatória entre pensamento e imagem (MACIEL, 2002, p. 99).

Algumas questões pertinentes à representação espacial referem-se a: como o lugar é percebido pelo indivíduo? Tais lugares têm a mesma significação ou/e se os símbolos visualizados no lugar possuem os mesmos sentidos a todos os usuários? Como se dá a significação e a representação social dos elementos da barranca do rio Pitangui e do Reservatório de Alagados?

Na obra 'Olhar periférico', Ferrara (1990), destaca que as representações sociais são:

[...] os sinais, as marcas que os processos de transformação social deixam no espaço e no tempo contando uma história não-verbal que se nutre de imagens, máscaras, fetiches concretizados em usos, hábitos, valores, expectativas, que por sua vez, se fetichizam em materiais... e objetos que povoam o cotidiano. (FERRARA, 1990, p. 106). 
Na tentativa de classificar os geossímbolos do território da pesca de lazer no Rio Pitangui, apropriou-se da definição de representação social de Serge Moscovici (2007) enquanto ato cognitivo, em que ancorar, ou seja, dar um sentido a um objeto, é classificar e dar nome a algo, isto é, se atribuirmos nome ao desconhecido, podemos imaginá-lo e representá-lo.

Nas palavras do autor, quando classificamos algo, ficamos restritos a um conjunto de comportamentos e regras que determinam o que é ou não é permitido ou característico em relação aos indivíduos pertencentes à determinada classe. Da mesma forma buscamos identificar qual característica, motivação ou atitude o torna distinto daquele grupo. $\mathrm{Na}$ verdade, é dada uma identidade social ao que não estava identificado, ajustando-o a uma representação social dominante (MOSCOVICI, 2007).

Por sua vez, a transposição de um esquema de representação cognitivo para o quadro de referência atual coloca-nos diante de uma situação em que a explicação dos fenômenos observados decorre dos marcos cognitivos do observador imerso no próprio sistema social que, por sua vez, define regras de pensamento e comportamento dos atores sociais, que se estabelecem dentro de estruturas econômicas, políticas e ideológicas determinadas, legitimando um conjunto de práticas e processos sociais para certos fins (FLORIANI, D., 2004, p. 33-34; LEFF, 2001, p. 121).

Portanto, o processo cognitivo - que envolve a aquisição, a representação da informação e a sua transformação em conhecimento - articula os discursos com uma classe de objetos possíveis de serem conhecidos por um determinado grupo, construídos por uma racionalidade que identifica e classifica esses objetos (FLORIANI et al, 2009).

Para entender a força dessas resentações como construtiva das do corpo de conhecimentos acerca da paisagem ribeirinha se faz necessário entender as produções materiais e simbólicas engendradas na territorilização desta prática sociocultural e, consequentemente, na reafirmação identitária de um modo de vida sobre (ou junto a) outros.

Isso posto, $\mathrm{O}$ ato de pescar e de "passar o tempo" nos acampamentos demanda da necessidade de práticas lazer pelos trabalhadores rurais. Os acampamentos, mais que locais de pesca, tornam-se lugares da sociabilidade e introspecção, o descanso do trabalho diário nas chácaras e fazendas. Geralmente, a pesca e a permanência nos acampamentos são feitas após o termino das atividades nas fazendas, nos dias de folga, finais de semanas e nos feriados. Os acampamentos acabam se tornando um local do lazer entre os trabalhadores de uma mesma fazenda. 
A maneira como os pescadores da área em questão se apropriam da barranca do rio dão uma configuração singular à paisagem fluvial: na barranca do rio ocorre a montagem dos acampamentos com os materiais utilizados e confeccionados muitas vezes nesses mesmos locais, de maneira simples e rudimentar, mas mesclados à artefatos da pesca esportiva e convencional modernos.

Observa-se, por outro lado, a apropriação desses locais por outra categoria de usuários, pessoas da cidade que conhecem e usufruem desses acampamentos, refletindo um fluxo centrífugo da cidade em direção às áreas rurais. É provável que a percepção dos trabalhadores e dos demais usuários sobre a barranca do rio e o ato da pesca seja diferenciada conforme cada grupo ou/e que estes compartilhem algumas percepções sobre cada ponto de pesca, diferenciando, por outro lado, em alguns elementos do complexo cultural da pesca (alguns traços materiais como artefatos e instrumentos da pesca - ou traços imateriais como saberes locais, toponímias e técnicas), representações da natureza do ambiente ribeirinho (de sua fragilidade ou estabilidade) e usos diferenciados.

Em suma, a compreensão e análise as ações cotidianas do pescador em relação ao lugar da pesca, entendido como um espaço íntimo (de introspecção) e como um espaço de relação inter-trans-subjetiva (entre pescadores e entre pescador e ambiente) torna-se extremamente importante e necessário a um estudo sobre a paisagem e os sujeitos que convivem e (re) criam o espaço da pesca de lazer. Uma possível abordagem desse estudo é a interpretação da narrativa comum como instrumento investigativo dos saberes e técnicas associadas à pesca vernacular.

Com base no exposto acima, o estudo dos "saberes" e "fazeres" relacionados à pesca vernacular praticada por trabalhadores e moradores nas áreas rurais das subbacias do Pitangui-Jotuba e turistas oriundos do meio urbano é uma questão a ser estudada. Partindo do pressuposto que esses saberes e fazeres são dinâmicos e constituintes do universo simbólico dos sujeitos pesquisados, tais fenômenos podem ser captados e interpretados pelo pesquisador de maneira implícita (nas narrativas dos entrevistados) e explicitamente, a partir dos artefatos de pesca, ou no registro das técnicas utilizadas pelos diferentes grupos de pescadores: urbanos e rurais.

\section{Geossímbolos da pesca amadora na paisagem fluvial dos rios Pitangui - Jotuva}


Os geossímbolos podem ser definidos por Joel Bonnemaison (2002) como sendo

[...] um lugar, um itinerário, uma extensão que, por razões
políticas, religiosas ou culturais, aos olhos de certas pessoas e
grupos étnicos assume um dimensão simbólica que os fortalece
em sua identidade [...] uma forma de linguagem, um instrumento
de comunicação partilhado por todos e, em definitivo, o lugar
onde se inscreve o conjunto da visão cultural"
(BONNEMAISON, 2002, p.109 e 124 ).

Dessa forma, as paisagens retêm a atenção de quem as observa, uma vez que ela se constitui no suporte das representações individuais e sociais dos indivíduos e grupos de indivíduos que criam/recriam os mesmos territórios que as compõem: uma territorialidade é impressa nas paisagens que, por intermédio de seus geossímbolos, dá sentido a ação de um grupo que imprime marcas identitárias que permitem delimitar um dado território, demonstrando e reafirmando a territorialidade do grupo.

Disso decorre o fato que cada grupo social possuir uma interação particular com o seu espaço de vivencia, criado a partir de sua visão de mundo e de uma organização social, regida por projetos coletivos e/ou interesses individuais; assim, cada grupo exerce suas atividades diárias (cotidianas e passadas) no espaço sobrepondo e opondo limites territoriais.

Os geossímbolos da pesca vernacular (acampamentos, artefatos, caminhos, etc) remetem à necessidade que os pescadores têm em reproduzir seu modo de vida rural na barranca do rio: os ranchos, por sua localização e representação da estrutura das casas é o ponto de referência e o local onde são armazenadas e confeccionados os artefatos, como bancos de madeira e tarimbas. Tais elementos acabam possuindo um sentido maior se analisarmos a sua importância no contexto da atividade da pesca de lazer. É o lugar do preparo da alimentação e do descanso, onde a fogueira é o ícone central entre os geossímbolos por ser o espaço de socialização e transmissão de valores, dos ideótipos de sociedade e natureza, de rememorização das histórias das famílias com a configuração do território.

Seguindo essa proposição, o processo de configuração do território da pesca ganha corpo com o desenvolvimento de uma rede de lugares hierarquizados compostos por acampamentos, ranchos e pontos de pesca e também por itinerários ou vias (os 'carreiros') que seguem os padrões de deslocamento conforme as representações (imaginários) que esse grupo social constrói sobre a paisagem ribeirinha.

Assim, as práticas da pesca amadora na Região dos Campos Gerias podem ser interpretadas mais propriamente aos rituais do lazer do que propriamente à pesca enquanto atividade produtiva; isto é, a escolha de um 
local para a pesca pode muitas vezes estar associado à vocação de uma dada área em possibilitar a prática de rituais de socialização os mais diversos: ligados à alimentação, à valores estéticos da paisagem, isto é, à relação entre sagrado e profano que um lugar pode apresentar a uma dada coletividade.

Não obstante, ademais dos aspectos imateriais das práticas da pesca, uma leitura material dos artefatos e técnicas de pesca foi também agenciada no intuito de evidenciar possíveis padrões de produção dos objetos na paisagem fluvial: nas barrancas do Rio Pitangui e seus principais afluentes, especialmente o Rio Jotuba, e nas margens da Represa de Alagados evidenciou-se semelhanças no uso e produção de materiais, assim como na caracterização do espaço nos pontos de pesca. Cabe destacar que a classificação dos objetos e das técnicas de pesca observados foram descritos tendo por base as bibliografias especializadas em pesca artesanal (SILVA, 1968; FABICHAK,1922; MOREIRA, 1980; KEIZI, 1997).

As observações in loco permitiram, portanto, conectar artefatos aos elementos e fatores bióticos e abióticos que determinam a utilização da paisagem ribeirinha, permitindo lançar hipóteses sobre o modelo cognitivo dos pescadores acerca da paisagem ribeirinha: as diferentes fisionomias da paisagem ribeirinha constituídas pela diversidade de componentes e processos abióticos (litologias, de solos, geomorfologias fluviais, vazão e velocidade do leito do rio) e bióticos (vegetação, ictioofauna, avifauna, etc) conectam-se aos instrumentos da pesca, dos objetos e edificações nos locais de pesca ao longo do curso do rio Pitangui, possibilitando tecer conjecturas sobre os modos de apropriação da natureza.

Os rituais e as técnicas que envolvem a organização da pesca estão aderidos à construção e organização espacial dos locais com potencial de pesca, existindo diversas formas e técnicas de montagens dos acampamentos e das fogueiras. Uma tipologia foi proposta para os acampamentos observados, sendo categorizados como 'Permanentes', 'Temporários' e 'Sazonais' (de veraneio). Essa tipologia é proposta a partir de observações de um total de 12 edificações distribuídas na área pesquisada (ver Figura 02).

Os acampamentos permanentes são construídos em madeira, com estrutura geralmente feita com troncos de árvores do próprio local de construção. Tem em média entre 8 a 24 metros quadrados e estão localizados a cerca de 5 metros do leito do rio geralmente em locais de barranco mais elevado e de solo estável. Ficam em pontos de pesca marcados por barranco íngreme e quase sempre assentes sobre intrusões graníticas. Possuem portas e janelas de madeira. Contam com fogão a lenha e tem uma cobertura lateral onde são guardadas varas, redes e caixas de abelha. 


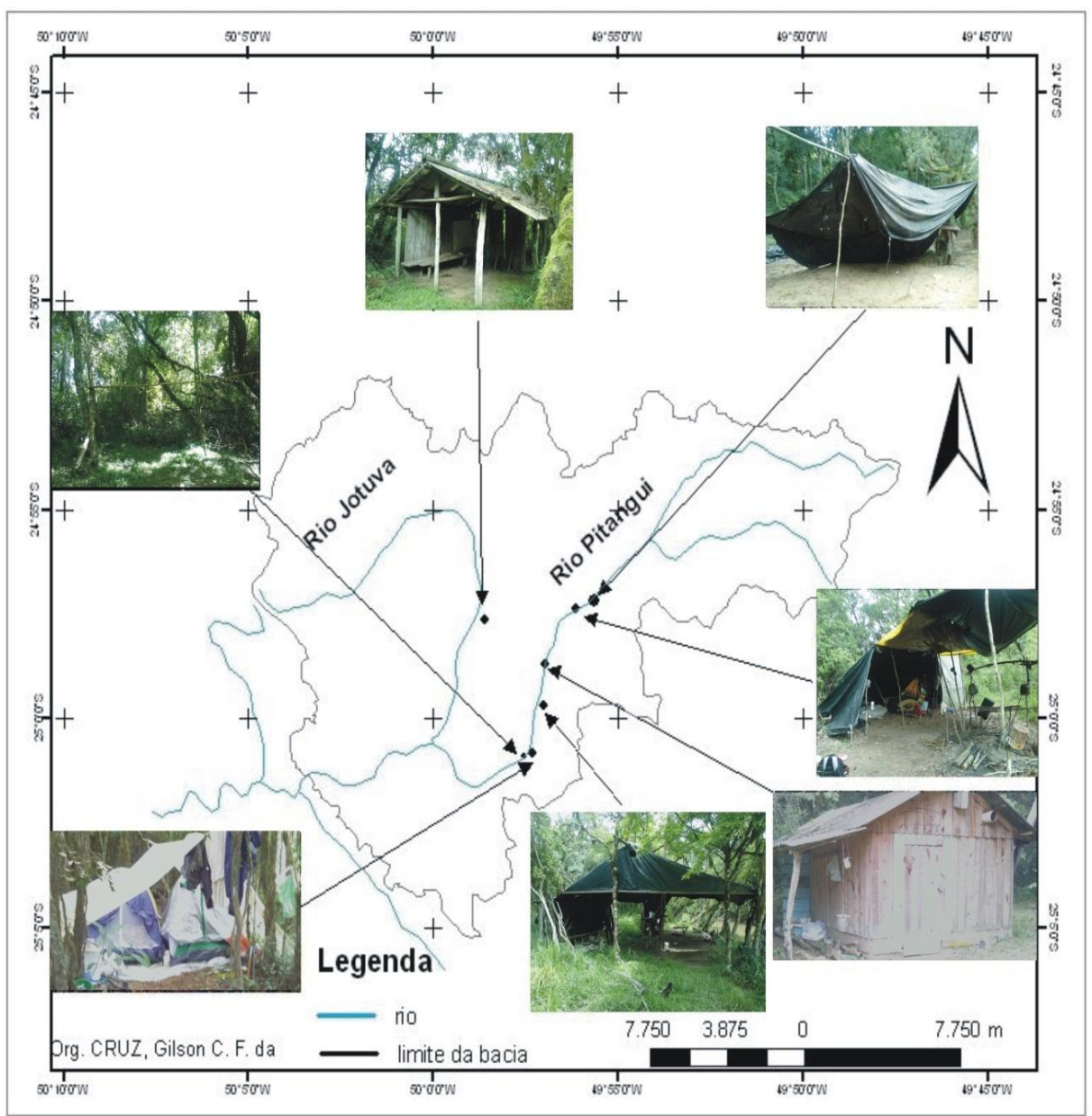

Figura 01: Mapa de localização de pontos de pesca, ranchos/acampamentos da área de estudo da paisagem fluvial do rio Pitangui/Jotuva.

Elaboração: SCHEIBEL (2013)

Os acampamentos temporários são construídos com materiais diversos, sobressaindo-se geralmente, o poliuretano preto de dois milímetros de espessura, usado como cobertura de implementos agrícolas ou forro de espaços de silagens nas fazendas. Nesses acampamentos observou-se que todos os materiais usados pelos pescadores são deixados nos locais e respeitados pelos demais usuários que frequentam esses pontos de pesca. Os pescadores trazem apenas os gêneros alimentícios e as iscas que usam nas pescarias e alguns apetrechos de pesca. 
Tabela 01: Indicação das coordenadas geográficas, tipologia dos acampamentos e pontos de pesca.

\begin{tabular}{|c|c|c|}
\hline Pontos Descritos & Coordenadas Geográficas & Categoria \\
\hline 01 & $24^{\circ} 56^{\prime} 378^{\prime \prime} \mathrm{S}-4^{\circ} 55^{\prime} 322^{\prime \prime O}$ & Acampamento Temporário \\
\hline 02 & $24^{\circ} 56^{\prime} 380^{\prime \prime} \mathrm{S}-4^{\circ} 55^{\prime} 327^{\prime \prime} \mathrm{O}$ & Ponto de Pesca \\
\hline 03 & $24^{\circ} 57^{\prime} 497^{\prime \prime} \mathrm{S}-49^{\circ} 55^{\prime} 861^{\prime \prime O}$ & Ponto de Pesca \\
\hline 04 & $24^{\circ} 57^{\prime} 588^{\prime \prime} \mathrm{S}-49^{\circ} 56^{\prime} 210^{\prime \prime} \mathrm{O}$ & Ponto de Pesca \\
\hline 05 & $24^{\circ} 57^{\prime} 588^{\prime \prime} \mathrm{S}-49^{\circ} 56^{\prime} 210^{\prime \prime O}$ & Acampamento Temporário \\
\hline 06 & $24^{\circ} 58^{\prime} 896^{\prime \prime S}-49^{\circ} 57^{\prime} 058^{\prime \prime O}$ & Rancho Permanente \\
\hline 07 & $24^{\circ} 59^{\prime} 778^{\prime \prime} \mathrm{S}-49^{\circ} 57^{\prime} 049^{\prime \prime} \mathrm{O}$ & Rancho Permanente \\
\hline 08 & $25^{\circ} 00^{\prime} 854^{\prime \prime} \mathrm{S}-49^{\circ} 57^{\prime} 517^{\prime \prime} \mathrm{O}$ & Local de Acampamento \\
\hline 09 & $25^{\circ} 01^{\prime} 156^{\prime \prime} \mathrm{S}-49^{\circ} 58^{\prime} 520^{\prime \prime} \mathrm{O}$ & Ponto de Pesca \\
\hline 10 & $25^{\circ} 00^{\prime} 781^{\prime \prime} \mathrm{S}-49^{\circ} 57^{\prime} 374^{\prime \prime} \mathrm{O}$ & Acampamento de Veraneio \\
\hline 11 & $24^{\circ} 57^{\prime} 549^{\prime \prime} \mathrm{S}-49^{\circ} 58^{\prime} 593^{\prime \prime} \mathrm{O}$ & Rancho Permanente \\
\hline 12 & $24^{\circ} 55^{\prime} 068^{\prime \prime} \mathrm{S}-49^{\circ} 59^{\prime} 472^{\prime \prime O}$ & Acampamento de Veraneio \\
\hline
\end{tabular}

Fonte: Scheibel (2013)

Quanto aos acampamentos de veraneio, foi observada apenas uma ocorrência, com duas barracas de camping e uma cobertura de poliuretano preto sobre um fogão improvisado.

A maior parte dos acampamentos observados constituem-se de materiais rústicos incluindo varas fixadas ao solo com amarras feitas por "cordas", arames ou cordames feitos com fibras de "embira" (planta fibrosa usada para a confecção de cordas) sobre os quais coloca-se e fixa-se uma "lona" manta de poliuretano) usada originalmente na cobertura das safras e dos maquinários agrícolas nas fazendas. Outros acampamentos, mais elaborados, foram feitos de madeira - os chamados "ranchos de pesca". Foram encontrados 05 acampamentos fixos e 05 temporários e um de veraneio. Alguns desses acampamentos existem há mais de 10 anos (números 06, 07 e 11). A localização desses acampamentos está representada na tabela 1 e na figura 1.

Os Ranchos observados se constituem em locais estratégicos, quer seja pela facilidade de acesso, pelo local mais elevado da margem do rio ou pela concentração de peixes (pesqueiros). Também, que esses locais se constituem em modelos representativos dos demais ranchos, acampamentos e pontos de pesca localizados nessa pesquisa (tabela 1).

As informações relativas aos geossímbolos (construções, caminhos, instrumentos) da pesca vernacular foram obtidas a partir das observações participantes e sintetizadas no quadro 1 . 
Quadro 01: Geossímbolos da pesca vernacular da paisagem fluvial do rio PitanguiJotuva.

A) Com relação aos instrumentos de pesca, tais como a vara e o anzol (caniço simples), a "linhada" ou "linha de mão", com linha de monofilamento de nylon, chumbada e boia, os suportes de varas, as "forquilhas" - cortadas no local e afixadas ao solo para deixar a vara em "descanso" até que o peixe puxe o anzol e seja "fisgado", "os desenroscadores de anzóis", compostos de uma vara longa com forquilha, geralmente cortada no ponto em que o pescador encontrou um "poço bom de pesca". Esses desenroscadores permitem que se recupere o anzol, toda vez que um "bagre" leve o material para as raízes entrelaçadas do fundo do rio. Isso é comum a todas as barrancas dos rios dessa bacia, sejam eles de fundo arenoso ou rochoso. Os caniços utilizados pelos pescadores/moradores da área rural, geralmente são confeccionados com uma vara de taquara com cerca de um metro a dois metros de comprimento, com uma ponta mais resistente ou mais flexível, dependendo da espécie a ser capturada onde se prende a linha com chumbada e anzol. A ponta do caniço e o nylon a serem utilizados devem ser mais finos para pesca do lambari (Astyanax altiparanae, Astyanax Fasciatus e Astyanax aff. Paranae) e do acará (Geofagus brasiliensis) e mais grossos para a pesca do bagre (Rhamdia quelen) e da traíra (Hoplias malabaricus). Na linha de nylon é colocada uma chumbada mais pesada para manter o anzol no fundo, na pesca do bagre e do acará e, mais leve, para a pesca do lambari. O uso de boias e "peninhas" "é mais frequente na pesca do lambari. O mesmo procedimento de montagem deste apetrecho é seguido com as varas industrializadas, sejam elas de taquara ou de materiais sintéticos, como a fibra de vidro e similares. Nos locais em que os pescadores passam uma ou duas noites observa-se a existência de panelas para o preparo de arroz, feijão e um cozido de verduras com carne além do café, que em alguns casos pode ser feito sem coador, onde o pó é adicionado diretamente na água fervente e decantado com uma "brasa" retirada do fogo e jogada diretamente no recipiente com a água em fervura. B) Com relação ao geossímbolos: 'fogueira', algumas delas são montadas com o intuito de preparar a alimentação e também como forma de produzir fumaça para espantar os "borrachudos", e pernilongos, comuns às áreas úmidas e cobertas de vegetação. Em algumas delas observam-se montagens de quatro pequenas forquilhas que servem de suporte onde são colocadas duas varas que mantêm os espetos na altura correta para a carne ser assada. Colocam-se pedras ou tocos mais grossos ao lado das fogueiras como quebra vento e direcionador das temperaturas. C) Os acampamentos em locais permanentes nos que o pescador tem autorização do proprietário (fazendeiro) para acampar, os materiais observados englobam churrasqueiras de tijolos, bancos, mesas, fogões e estrados de madeira que servem como camas. Normalmente usa-se uma enxada ou cortadeira para escavar e encontrar a isca mais comum de pesca nesses locais, a minhoca e também o "minhocoçu" ou "minhocão-do-banhado". Este é maior e de consistência mais rígida ao ataque dos peixes, permanecendo por mais tempo e impedindo que os lagostins e caranguejos de água doce, "os carniceiros do rio", retirem rapidamente a isca do anzol na linhada, atrapalhando a pescaria. D) Outro símbolo característico aos locais de pesca é a existência das "pinguelas" (ponte improvisada com troncos, sem proteção e estreita), que se constituem em varas ou troncos colocados sobre as "valetas" e "sangas" "para a transposição desses locais, geralmente de pouca profundidade, mas que impede o deslocamento para os demais pontos de pesca ao longo do rio.

Fonte: SCHEIBEL (2013)

\footnotetext{
${ }^{2}$ Material confeccionado pelo pescador ou adquirido em lojas de pesca, a partir de penas de aves, geralmente de patos.

${ }^{3}$ Os borrachudos ou pium são dípteros pertencentes à família Simuliidae.

${ }^{4}$ Pequeno riacho, córrego, com nascente própria e que geralmente deságua em rios ou lagos.
} 


\section{Etnoecologia do ambiente ribeirinho: saberes locais sobre a paisagem fluvial dos rios Pitangui e Jotuva e imaginários da fertilidade do rio}

Os produtos da relação entre pescadores e a paisagem ribeirinha permite vislumbrar a questão da representação social relatada por Moscovici (2007, p.225) em que ancorar "é classificar e dar nome a algo". Se atribuirmos nome ao desconhecido, podemos imaginá-lo e representá-lo. Ainda nas palavras desse autor, quando classificamos algo, ficamos restritos a um conjunto de comportamentos e regras que determinam o que é ou não permitido ou característico em relação aos indivíduos pertencentes à determinada classe. Da mesma forma buscamos identificar qual característica, motivação ou atitude o torna distinto daquele grupo, a partir da qual é dado um sentido coletivo ao que não estava identificado, ajustando-o a uma representação social predominante que, por sua vez predispõem o grupo a determinadas práticas sobre o espaço.

Ora, as representações sociais possibilitam-nos "compreender como o indivíduo ou a coletividade interpreta a realidade de uma sociedade, expressando o conhecimento que cada pessoa ou grupo detém sobre um determinado tema" (ROCHA \& AMORAS, 2006, p. 149).

Neste sentido, acreditamos que as representações sociais dos sujeitos da pesca são reveladoras das formas de relações entre sujeitos e ambiente fluvial e, portanto, dos conhecimentos locais acerca dos ambientes.

As conversas informais (entrevistas abertas) permitiram estabelecer um espaço de relativa confiança e diálogo, posto que a maioria dos entrevistados temia a coerção da Policia Florestal e a fiscalização de agentes do Instituto Ambiental do Paraná ou da Força Verde. Após o contato inicial, superada a desconfiança, foram realizadas observações e entrevista em meio à prática da pesca, sobre o conhecimento dos pescadores referente à taxonomia e aos nomes vulgares das espécies mostradas em pranchas de imagens, ao comportamento e hábitos alimentares dos peixes, reconhecimento das características físicas dos peixes e à ecologia das espécies de peixes apresentadas, bem como os materiais e práticas da pesca das espécies.

Assim, a partir da formulação de três perguntas abertas e gerais, relativas aos aspectos das relações produtivas com o ambiente ribeirinho, foi possível estabelecer diferenciações entre os perfis dos pescadores entrevistados que frequentam o RPRJ: a) $\mathrm{O}$ que o Rio Pitangui representa para você enquanto ambiente natural? b) O que é um rio bom de pesca? c) Quais desses atributos naturais você opta quando escolhe o local para pesca?

As informações obtidas por meio da observação participante, junto aos 12 sujeitos entrevistados (Quadro 02) com o apoio de recursos iconográficos 
(fotografias de espécies de peixes locais), revelaram um corpo de conhecimentos ecológico sobre as espécies-alvo: a taxonomia vernacular, os locais e períodos de capturas, os períodos de migração, os nichos ecológicos, entre outros, sistematizado conforme a quadro 3.

Quadro 02: Perfil socioeconômico dos pescadores residentes locais

\begin{tabular}{|l|l|l|l|l|l|l|}
\hline PESCADOR & SEXO & $\begin{array}{l}\text { IDADE } \\
\text { anos })\end{array}$ & $\begin{array}{l}\text { NÍVEL DE } \\
\text { ESCOLARIDADE }\end{array}$ & $\begin{array}{l}\text { RENDA MÉDIA } \\
\text { MENSAL } \\
\text { (Salário } \\
\text { Mínimo })\end{array}$ & $\begin{array}{l}\text { CIDADE DE } \\
\text { ORIGEM }\end{array}$ & $\begin{array}{l}\text { TEMPO } \\
\text { PESCA } \\
\text { NO RPRJ }\end{array}$ \\
\hline 01 & $\mathrm{M}$ & 70 & $1^{\circ} \mathrm{Grau}$ & 01 & Carambeí & 50 anos \\
\hline 02 & $\mathrm{M}$ & 38 & $1^{\circ} \mathrm{Grau}$ & 02 & Carambeí & 20 anos \\
\hline 03 & $\mathrm{M}$ & 58 & $1^{\circ} \mathrm{Grau}$ & 01 & Carambeí & 15 anos \\
\hline 04 & $\mathrm{M}$ & 55 & $1^{\circ} \mathrm{Grau}$ & 01 & Carambeí & 40 anos \\
\hline 05 & $\mathrm{M}$ & 48 & $1^{\circ} \mathrm{Grau}$ & NI* & Carambeí & 30 anos \\
\hline 06 & $\mathrm{M}$ & 57 & $3^{\circ} \mathrm{grau}$ & Mais de 08 & Carambeí & 30 anos \\
\hline 07 & $\mathrm{M}$ & 70 & $2^{\circ} \mathrm{Grau}$ & 03 & Carambeí & 50 anos \\
\hline 08 & $\mathrm{M}$ & 58 & $1^{\circ} \mathrm{Grau}$ & 02 & Carambeí & 40 anos \\
\hline 09 & $\mathrm{M}$ & 64 & $1^{\circ} \mathrm{Grau}$ & 01 & Carambeí & 40 anos \\
\hline 10 & $\mathrm{M}$ & 42 & $1^{\circ} \mathrm{Grau}$ & 02 & Carambeí & 30 anos \\
\hline 1102 & $\mathrm{M}$ & 53 & $1^{\circ} \mathrm{Grau}$ & 02 & Carambeí & 39 anos \\
\hline 12 & $\mathrm{M}$ & 59 & $1^{\circ} \mathrm{Grau}$ & 02 & Carambeí & 40 anos \\
\hline
\end{tabular}

Fonte: SCHEIBEL (2013)

Obs. N.I* - Não Informado

A interpretação das narrativas dos pescadores residentes na área rural resultou em uma quantidade considerável de informações sobre as espécies existentes e respectivos nomes comuns; seus hábitos e seus habitat confirmando a existência de um corpo de conhecimentos ecológicos acerca da paisagem ribeirinha, sintetizados conforme Quadro 03.

Quadro 03: Sistema taxonômico ecológico local acerca da paisagem fluvial dos rios Pitangui e Jotuva.

1) os pescadores do Rio Pitangui reconhecem 14 espécies existentes na área de pesquisa (12 apresentadas nas pranchas e mais duas citadas, a Curimba e a Tuvira). Duas espécies não foram indicadas como existentes na área de pesquisa (peixes 02 e 05 ); 2) os pescadores relacionam o período de maior produtividade da pesca com os períodos diuturnos e noturnos; com a estação do ano (verão); épocas de chuvas e com o período da piracema; 3 ) a existência de outras espécies não apresentadas nas pranchas de pesquisa; 4) o conhecimento sobre o período da Piracema e 
movimento migratório dos peixes; 5) o uso de vários nomes dados a uma mesma espécie. Como exemplos cita-se: os termos "tarrasquinha", "riata" ou "arriata" e "cambeva" ou "cambeba" para a espécie Trychomycterus diabolus (guasca), 6) para as espécies semelhantes de lambaris (Astyanax altiparanae, Astyanax fasciatus e Astyanax aff. Paranae) classificam como sendo um uma única espécie, sendo citados como "Lambari relógio". Outra espécie, Oligosarcus paranensis (Saicanga) foi citada como "Lambari" ou "Lambari-Saicanga".O termo lambari é usado para designar subespécies ou outras espécies com aspectos visuais semelhantes (peixes pequenos de escamas). Também houve a citação do termo "guaru" para lambaris de pequeno porte. Nas palavras do pescador E. (53 anos) "Nós pescamos muitos guarus nesse local" (no rio Jotuva).O termo comum "guaru" é corresponde na classificação cientifica à espécie Phalloceros cf. Harago; 7) Outra constatação é da proliferação de caranguejos de água doce (Crustácea: Decapoda: Brachyura), espécie não identificada cientificamente nessa pesquisa. Os pescadores afirmaram que o caranguejo existe em quantidade no inverno e em outras épocas do ano. Segundo o pescador J. (63 anos), "Se você for pescar no inverno só vai pegar caranguejo! Esse bicho dá como praga no rio! Dificultam a pescaria". Porém, não informaram o que fazem com o caranguejo que capturam na linha; 8) Na relação da pesca do bagre com a captura acidental dos caranguejos, os pescadores demonstram conhecimento da rede alimentar: “...os bagres são peixes de fundo. São 'porcos do rio', pois comem de tudo. Comem caranguejos! Os caranguejos também comem os peixes fisgados ou presos em redes". Outras referências da cadeia alimentar são relatadas na pesca da traíra e do lambari: "as traíras se alimentam de outros peixes, principalmente de lambaris". Também que “...os lambaris comem até as ovas de outros peixes". Dessas afirmações percebe-se um sistema de conhecimento da cadeia alimentar, em relação aos peixes e outros organismos aquáticos; 9) Os conhecimentos da pesca são associados à profundidade do leito do rio ("poços") e às condições de turbidez da água ("águas barrentas"), à existência de vegetação aquática e locais associados ao ambiente fluvial, como lagoas em meandros do rio e várzeas (áreas permanentemente alagadas), aos locais com pedras ou "pedreiras"; 10) no que tange ao peso das espécies capturadas, as indicações são de exemplares maiores no verão, geralmente não ultrapassando $1,5 \mathrm{Kg}$ de peso para bagres e traíras. No inverno há poucas capturas, sendo a maioria de peixes pequenos, conforme a citação do pescador João (52 anos): "Você só vai pegar peixinhos desse tamanho (pequenos). Não dá peixe nessa época! É perda de tempo pescar"; 11) em relação ao sexo dos peixes, a maioria das respostas indicou relação aos ovários maduros. Aparecem controvérsias que peixes machos também possuem ovas: conforme a pergunta do pescador Luiz (70 anos) feita ao pesquisador "Como você explica que entre sessenta lambaris capturados, todos sejam fêmeas, já que estão ovadas, e não se capture nenhum macho? Qual é a explicação cientifica para esse fato." Outra questão feita pelo mesmo pescador: "Como uma lagoa isolada e sem ter sido povoada por alguém pode depois de algum tempo ter peixes, principalmente traíras?" Essas duas questões povoam o imaginário desses pescadores; 12) com relação aos ambientes de capturas, os pescadores indicaram: "a traíra [Hoplias malabaricus] se pesca nos capinzieros. O cará [Geofagus brasiliensis] é pescado nas margens e em banhados ou locais com vegetação aquática". A carpa [Ciprinus carpus] é pescada em locais de ceva com massas preparadas com substâncias que dão um 'cheirinho na massa', o que atrai as carpas". Segundo esse mesmo pescador, a maior carpa pescada nesse sistema chegou a 20 quilos. Outro pescador confirmou esse relato afirmando a captura de espécie com 17 quilos. Essas carpas segundo esses pescadores sobem o rio no verão e são frequentes em outras épocas do ano.

Fonte: SCHEIBEL (2013)

Com o auxílio de pranchas fotográficas de espécies catalogadas no trecho do rio Pitangui (GEALH et al, 2010) foi possível confirmar ou refutar 
informações acerca dos peixes conhecidas pelos pescadores da região. A observação participante possibilitou estabelecer relativos laços de confiança entre o pesquisador (também pescador) e os sujeitos da pesquisa. Buscou-se manter durante as conversas os termos e expressões coloquiais utilizadas pelos sujeitos, referenciando o tema em questão no nível das práticas cotidianas do entrevistado, bem dar destaque, durante a entrevista, ao caráter prescritivo das ações (as recomendações dos pescadores) frente às supostas dificuldades encontradas no ato da pesca.

Assim, com base nas técnicas participativas de diagnóstico e prognóstico das práticas da pesca, foi possível coligir dados relativos às espécies pescadas, aos habitats das espécies, à piscosidade do ambiente, ao período de pesca e às técnicas e artefatos utilizados. Esses dados estão sistematizados no quadro 4.

Quadro 04: Matriz cognitiva da pesca vernacular da paisagem ribeirinha dos rios Pitangui e Jotuva.

\begin{tabular}{|c|c|c|c|c|c|}
\hline $\begin{array}{c}\text { ESPÉCIE } \\
\text { (NOME POPULAR) }\end{array}$ & $\begin{array}{l}\text { RECONHECI- } \\
\text { MENTODE } \\
\text { ESPÉCIE }\left(\mathbf{N}^{o}\right)\end{array}$ & AMBIENTE & $\begin{array}{l}\text { PISCOSI- } \\
\text { DADE }\end{array}$ & $\begin{array}{l}\text { ARTEFATOS/ } \\
\text { TÉCNICAS }\end{array}$ & $\begin{array}{l}\text { PERÍODO } \\
\text { DA PESCA }\end{array}$ \\
\hline $\begin{array}{l}\text { Trychomycterus } \\
\text { Diabolus (guasca) }\end{array}$ & $\operatorname{Sim}(6)$ & $\begin{array}{l}\text { Troncos, } \\
\text { pedras, leito. }\end{array}$ & Baixa & Linha e anzol & $\begin{array}{l}\text { Águas } \\
\text { barrentas e a } \\
\text { noite }\end{array}$ \\
\hline $\begin{array}{l}\text { Trychomycterus sp. } \\
\text { (Guasca) }\end{array}$ & $\begin{array}{l}\text { Confusão com } \\
\text { espécie anterior } \\
\text { (2) }\end{array}$ & $\begin{array}{l}\text { Troncos, } \\
\text { pedras, leito. }\end{array}$ & Baixa & Linha e anzol & $\begin{array}{l}\text { Águas } \\
\text { barrentas e a } \\
\text { noite }\end{array}$ \\
\hline $\begin{array}{l}\text { Hypostomus regani } \\
\text { (Cascudo) }\end{array}$ & $\operatorname{Sim}(5)$ & $\begin{array}{l}\text { Locais com } \\
\text { pedras e } \\
\text { galhadas }\end{array}$ & Baixa & $\begin{array}{l}\text { Redes de } \\
\text { espera }\end{array}$ & $\begin{array}{l}\text { À noite, em } \\
\text { redes de } \\
\text { espera. }\end{array}$ \\
\hline $\begin{array}{l}\text { Hypostomus } \\
\text { albopunctatus } \\
\text { (Cascudo) }\end{array}$ & $\begin{array}{l}\text { Sim (confusão } \\
\text { com a espécie } \\
\text { anterior) - (1) }\end{array}$ & $\begin{array}{l}\text { Locais com } \\
\text { pedras e } \\
\text { galhadas }\end{array}$ & Baixa & $\begin{array}{l}\text { Redes de } \\
\text { espera }\end{array}$ & $\begin{array}{l}\grave{A} \text { noite em } \\
\text { redes de } \\
\text { espera }\end{array}$ \\
\hline $\begin{array}{l}\text { Imparfinis schubarti } \\
\text { (Bagrinho) }\end{array}$ & Não & - & - & - & - \\
\hline $\begin{array}{l}\text { Rhamdia quelen } \\
\text { (Bagre ou Jundiá) }\end{array}$ & $\operatorname{Sim}(12)$ & $\begin{array}{l}\text { Poços, } \\
\text { margens e } \\
\text { todo o leito } \\
\text { do rio nos } \\
\text { dias de } \\
\text { chuva. }\end{array}$ & $\begin{array}{l}\text { Alta nos } \\
\text { períodos } \\
\text { citados }\end{array}$ & $\begin{array}{l}\text { Linha e anzol } \\
\text { com chumbada } \\
\text { mais pesada }\end{array}$ & $\begin{array}{l}\text { À noite e } \\
\text { durante o dia } \\
\text { em águas } \\
\text { barrentas }\end{array}$ \\
\hline $\begin{array}{l}\text { Hoplias malabaricus } \\
\text { (Traíra) }\end{array}$ & $\operatorname{Sim}(12)$ & $\begin{array}{l}\text { Vários locais } \\
\text { do rio }\end{array}$ & Baixa & $\begin{array}{l}\text { Linha e anzol, } \\
\text { na "Batida" e } \\
\text { com Linhas de } \\
\text { mão. }\end{array}$ & $\begin{array}{l}\text { Durante o } \\
\text { dia em } \\
\text { vários } \\
\text { períodos } \\
\end{array}$ \\
\hline $\begin{array}{l}\text { Oligosarcus } \\
\text { paranensis (Saicanga) }\end{array}$ & Sim (3) & $\begin{array}{l}\text { Sem lugares } \\
\text { específicos }\end{array}$ & Baixa & Linha e anzol & $\begin{array}{l}\text { Durante o } \\
\text { dia }\end{array}$ \\
\hline $\begin{array}{l}\text { Geofagus brasiliensis } \\
\text { (Cará ou Acará) }\end{array}$ & Sim (12) & $\begin{array}{l}\text { Margens } \\
\text { com capim e } \\
\text { em locais de } \\
\text { banhado }\end{array}$ & $\begin{array}{l}\text { Baixa a } \\
\text { alta }\end{array}$ & Linha e anzol & $\begin{array}{l}\text { Durante o } \\
\text { dia }\end{array}$ \\
\hline
\end{tabular}




\begin{tabular}{|c|c|c|c|c|c|}
\hline $\begin{array}{c}\text { ESPÉCIE } \\
\text { (NOME POPULAR) }\end{array}$ & $\begin{array}{l}\text { RECONHECI- } \\
\text { MENTODE } \\
\text { ESPÉCIE }\left(\mathbf{N}^{o}\right)\end{array}$ & AMBIENTE & $\begin{array}{l}\text { PISCOSI- } \\
\text { DADE }\end{array}$ & $\begin{array}{l}\text { ARTEFATOS/ } \\
\text { TÉCNICAS }\end{array}$ & $\begin{array}{l}\text { PERÍODO } \\
\text { DA PESCA }\end{array}$ \\
\hline $\begin{array}{l}\text { Oreochromis niloticus } \\
\text { (Tilápia) }\end{array}$ & Sim (rara) - (1) & $\begin{array}{l}\text { Sem local } \\
\text { especifico }\end{array}$ & $\begin{array}{l}\text { Muito } \\
\text { baixa }\end{array}$ & Linha e anzol & $\begin{array}{l}\text { Durante o } \\
\text { dia }\end{array}$ \\
\hline $\begin{array}{l}\text { Cyprinus carpio } \\
\text { (Carpa) }\end{array}$ & Sim (9) & $\begin{array}{l}\text { Leito e meia- } \\
\text { água }\end{array}$ & baixa & $\begin{array}{l}\text { Linha e anzol } \\
\text { em locais de } \\
\text { ceva }\end{array}$ & $\begin{array}{l}\text { Durante o } \\
\text { dia }\end{array}$ \\
\hline $\begin{array}{l}\text { Astyanax altiparanae } \\
\text { (Lambari relógio) }\end{array}$ & Sim (7) & $\begin{array}{l}\text { Em todos os } \\
\text { locais do } \\
\text { leito do rio }\end{array}$ & Alta & Linha e anzol & $\begin{array}{l}\text { Durante o } \\
\text { dia }\end{array}$ \\
\hline $\begin{array}{l}\text { Astyanax Fasciatus } \\
\text { (Lambari do rabo } \\
\text { vermelho) }\end{array}$ & $\operatorname{Sim}(12)$ & $\begin{array}{l}\text { Em todos os } \\
\text { locais do } \\
\text { leito do rio }\end{array}$ & Alta & Linha e anzol & $\begin{array}{l}\text { Durante o } \\
\text { dia }\end{array}$ \\
\hline $\begin{array}{l}\text { Astyanax aff. Paranae } \\
\text { (Lambari) }\end{array}$ & Sim (8) & $\begin{array}{l}\text { Em todos os } \\
\text { locais do } \\
\text { leito do rio }\end{array}$ & Alta & Linha e anzol & $\begin{array}{l}\text { Durante o } \\
\text { dia }\end{array}$ \\
\hline $\begin{array}{l}\text { Gymnotus } \\
\text { ineaquilabiatus ou } \\
\text { Eigenmannia } \\
\text { virescens (Tuvira, } \\
\text { Moreninha ou } \\
\text { Espadinha). }\end{array}$ & Sim (8) & $\begin{array}{l}\text { Sem citação } \\
\text { de locais }\end{array}$ & $\begin{array}{l}\text { Muito } \\
\text { baixa }\end{array}$ & Linha e anzol & $\begin{array}{l}\text { Durante o } \\
\text { dia }\end{array}$ \\
\hline
\end{tabular}

Fonte: SCHEIBEL (2013)

\section{Considerações finais}

Desse fato, a prática da pesca pode variar em sua qualificação: "amadora" ou de "lazer". Acreditamos que a pesca amadora denote uma relação produtiva com o meio, mas não central na economia doméstica (como é o caso da pesca artesanal ou moderna, onde se tem a existência do pescador profissional), embora obrigatória: há o dever de se pescar algo, ou pelo menos tentar fazê-lo, ao passo que a modalidade "lazer" indique uma relação extrativista facultativa, relevante e não contabilizada na economia doméstica do grupo.

A representação e as práticas de natureza na paisagem ribeirinha do Pitangui-Jotuva está atrelada à esfera do sagrado dos agricultores no momento do lazer, quando é possibilitada a ressignificação da história da relação das famílias com a região vivida: a reafirmação da identidade desse grupo de famílias sobre o mundo racional (da produção econômica) é possibilitada quando da apropriação desse ambiente em termos de práticas simbólicas (rituais de sociabilização) no ato da reinterpretação de suas histórias frente a novos contextos socioespaciais que atravessam e se impõem à região.

Nesse sentido, o saber-fazer da pesca vernacular desta região pode ser concebido como o termômetro da reprodução-adaptação deste modo de vida 
particular frente à ideologia (representação) hegemônica moderna da separação radical entre sociedade e natureza.

Ademais, a identidade dos grupos de famílias de agricultores é reconstruída frente às outras territorialidades que se impõem conflituosamente na disputa pelo território da paisagem fluvial: uma apoiada na institucionalização formal das políticas de proteção da natureza (os parques e as áreas de proteção permanente, em nível estadual e federal), outra expressa nas ações individuais espontâneas de pescadores de lazer de origem urbana.

Em todos os casos, as práticas das pescas vernacular (os agricultores habirantes da região) e exógena (os turistas urbanos), embora não acarretem necessariamente em impactos às unidades de paisagem - dado o tamanho e a intensidade de uso dos recursos naturais dos ranchos instalados nas matas - são tidas como práticas irregulares aos olhos da legislação ambiental, portanto, configuram-se como territorialidades clandestinas.

Ora, todas essas territorialidades estão ancoradas em distintos imaginários da natureza ribeirinha, por meio dos quais são agenciadas práticas de uso e/o não uso dos ecossistemas ripários, cujos desdobramentos dependem em última instância do nível de arraigo (pertencimento) dos atores ao lugar. É possível presenciar entre os agricultores da região práticas distintas e opostas: nas terras agricultáveis presenciam-se práticas guiadas por uma racionalidade econômico-instrumental, por outro lado, nas terras da floresta ripária presenciase uma racionalidade substantiva fundamentada em valores tradicionais a serem reproduzidos em práticas, símbolos e saberes da pesca vernacular.

\section{Referências}

AGIER, Michel. Lugares e redes: as mediações da cultura urbana. In: NIEMEYER, Ana. Maria. e GODOI, Emília Pietrafesa. (orgs.) Além dos territórios: para um diálogo entre a etnologia indígena, os estudos rurais e os estudos urbanos.

Campinas: Mercado das Letras, 1998. p. 41-64.

ALMEIDA, Alcionir Pazatto. A percepção da paisagem urbana de Santa Maria/RS e os sentimentos de topofilia e topofobia de seus moradores. 2007. Dissertação de Mestrado - UFSM, Santa Maria - RS. 118 p.

BACHELARD, Gaston. A poética do espaço. São Paulo: Ed. Martins Fontes, 1993.

BAUMAN, Zygmunt. Modernidad líquida. 6. ed., Buenos Aires: Grafinor S. A., Fondo de Cultura Econômica, 2002. 260p. 
BEGOSSI, Alpina. Org.; participantes, LEME, A.[et al.] Ecologia dos pescadores da Mata Atlântica e da Amazônia. São Paulo: Hucitec: Nepam/Unicamp: Nupaub/USP: FAPESP, 2004.

BONNEMAISON, Jöel.Viagem em Torno do Território. In: CORRÊA, Roberto L.; ROSENDAHL, Zeni (Org.).Geografia Cultural: um século. Rio de Janeiro: Ed. UERJ, 2002. P. 83-131

CHAMMA, G.V.F. Ponta Grossa: o povo a cidade e o poder. Prefeitura Municipal de Ponta Grossa, 1988. in MASSUQUETO, Lilian Patrícia. 2003. Potencialidades de turismo e uso acadêmico no sítio natural Cachoeira do Rio São Jorge - Ponta Grossa - PR. Ponta Grossa, 2003, 104p. Monografia (Graduação em Bacharelado em Geografia) - Setor de Ciências Exatas e Naturais, UEPG.

CONAPE. $1^{\circ}$ Encontro Nacional da Pesca Amadora - Construindo a política da Pesca Amadora - Documento Final do Encontro. MPA. Brasília - 01 e 02 de setembro de 2010. Disponível em:<

http://www.mpa.gov.br/mpa/seap/Jonathan/mpa3/pesca/docs/ENPA\% 20>. Acesso em 21/01/2010.

DE JULIO, Marcelo. et ali. Evolução histórica do sistema de abastecimento de água do município de Ponta Grossa/PR. Revista de Engenharia e Tecnologia. V. 2, No. 2, Ago/2010.

FERRARA Lucrécia. D'Alessio. Olhar periférico: informação, linguagem, percepção ambiental. São Paulo: Editora da Universidade de São Paulo, 1993.

Supraorgânico na Geografia Cultural Americana. In.: Revista Espaço e Cultura - no 13 - dezembro de 1996. Rio de Janeiro: UERJ/NEPEC - Semestral; jan./jun. de 2002; p.7-27;

FERREIRA, Aurélio Buarque de Holanda. Dicionário Aurélio Básico da Língua Portuguesa. Rio de Janeiro: Nova Fronteira, 1988, p. 214.

EMBRAPA - Empresa Brasileira de Pesquisa Agropecuária: Levantamento semidetalhado de solos: município de Carambeí - Estado do Paraná. Escala 1:100.000. Rio de Janeiro: EMBRAPA, 2002 ${ }^{\mathrm{a}}$, in (GEALH, MELO e MORO, 2010) . http://www.revistaret.com.br/ojs-2.2.3/index.php/ret/article/viewFile/32/70 (ETAs Pitangui)

FABICHAK, Irineu. Aprenda a pescar. Nobel, São Paulo - SP, 1923, 112 p. 
HOLANDA, A. B., 1988, Dicionário Aurélio Escolar da Língua Portuguesa, 1 ed., Editora Nova Fronteira, Rio de Janeiro, RJ

KEIZI, M. Vamos pescar? Nova Sampa. Itapevi - SP, 1997, 98 p.

MINISTÉRIO DA PESCA E DA AQUICULTURA. Pesca - Pesca Amadora: perguntas frequentes. MPA, 2012. Disponível em:< http://www.mpa.gov.br/\#pesca/perguntas-frequentes>. Acesso em 02/01/2012.

MOREIRA, Carlos. Os fundamentos na pesca de linha. Editora Tecnoprint S.A., Rio de Janeiro-RJ, 1980, 85 p.

MOSCOVICI, Serge. Representações sociais: investigação em psicologia social. (Tradução Pedrinho A. Guareschi) 5 ed. Petrópolis -RJ: Vozes, 2007.

PILATTI, Fernando. Recuperação ambiental em micro bacia do rio Tibagi Alagados. IX Encontro Nacional de Comitês de Bacias Hidrográficas. Foz do Iguaçu -23 a 27 de outubro de 2007. Disponível em:

<http://www.rebob.org.br/ENCBH/25outubro/Sala05/01PR22Alagados-Foz.pdf>. Acesso em 10/01/2012.

PRESIDÊNCIA DA REPÚBLICA. LEI N 11.959, de 29 de Junho de 2009. Disponível em:

<www.planalto.gov.br/ccivil_03/_Ato2007.../2009/Lei/L11959.htm>. Acesso em 26/01/2012.

SANTOS, Milton. O lugar e o Cotidiano. In: SANTOS, Milton. A natureza do espaço: técnica e tempo. Razão e emoção. 2. Ed., São Paulo: HUCITEC, 1997. p. 251-263.

SCHEIBEL, C.R. Práticas, técnicas e geossímbolos da cultura da pesca venacular na paisagem fluvial do Pitangui-Jotuva, região dos Campos Gerais (PR). 2013. 120 p. Dissertação (Mestrado em Gestão do Território), Setor de Ciências Exatas e Naturais, Universidade Estadual de Ponta Grossa.

SILVA, Oswaldo. Wenceslau. A pesca em rios e lagoas do Brasil. Forense, Rio de Janeiro, 1968, $117 \mathrm{p}$.

TUAN, Yi-Fu. Topofilia - Um estudo da percepção, atitudes e valores do meio ambiente. São Paulo: Difel, 1980. 290p.

* Este artigo é fruto de dissertação de mestrado em Gestão do Território desenvolvida junto ao Programa de Pós-graduação em Geografia da Universidade Estadual de Ponta Grossa, defendida em 2013. 


\section{Carlos Roberto Scheibel}

Geógrafo e Mestre em Gestão do Território pela Universidade Estadual de Ponta Grossa. Atualmente é professor da Secretaria de Estado da Educação do Paraná, no núcleo regional de educação - Ponta Grossa.

Endereço: Rua Carlos Osternack - 84040-120 - Ponta Grossa, PR

E-mail: schei@ superig.com.br

\section{Nicolas Floriani}

Engenheiro Agrônomo, Mestre em Ciências do Solo e Doutor em Meio Ambiente e Desenvolvimento pela Universidade Federal do Paraná. Atualmente é Professor Adjunto do Departamento de Geociências e do Programa de Pós-Graduação em Geografia da Universidade Estadual de Ponta Grossa. Bolsista Produtividade da Fundação Araucária. Av. Carlos Cavalcanti n 4748 - Uvarana - 84030900 - Ponta Grossa, PR E-mail: florianico@gmail.com

Recebido para publicação em abril de 2014 Aprovado para publicação em agosto de 2014 